\title{
Orthognathic surgery case overview in patients with class III dentoskeletal angle classification
}

\author{
Dimas Ilham Hutomo*, Ida Ayu Astuti*, Borman Sumaji** \\ *Department of Orthodontics Faculty Of Dentistry Universitas Padjadjaran \\ **Department of Oral and Maxillofacial Surgery Faculty of Dentistry Universitas Padjadjaran
}

\begin{abstract}
Introduction: Angle classification is a classification commonly used for malocclusion in the field of orthodontics. Mandibular prognation is one of the skeletal features of Class III dentoskeletal classification or defined as mesiocclusion. The prevalence of class III dentoskeletal occurrence in Asian populations is much higher than Caucasian racial populations. Aim of research is to obtain data of Orthognathic surgery case overview in patients with class III dentoskeletal angle classification Methods: Type of research is using a retrospective descriptive method by taking secondary data from medical record cards of orthognathic surgery cases. The population in this study were all medical record data of patients undergoing orthognathic surgical treatment in the Oral and Maxillofacial Surgery Department of RSUP Dr. Hasan Sadikin 2006-2011 period. The sample in this study is medical record data of patients with Class III dentoskeletal classification performed orthognathic surgery in the period 2006-2011. then classified by year of surgery, sex, age, Angle classification, state of anterior open bite, location of surgery, and technique used in surgery. Result: $2 \%$ of orthognathic surgical patients have a Class III Angle relationship and only $8 \%$ of orthognathic surgical patients have a Class II Angle relation. Based on the anterior tooth overbite relation in patients with an Angle class III relationship, there are 16 patients who have an open bite relation on the anterior teeth. Only 8 patients from Angle III class relationships were treated with orthognathy without an anterior open bite relation.Conclusion: In the period 2006-2011, the Department of Oral and Maxillofacial Surgery Dr. Hasan Sadikin handled 26 orthognathic surgical patients, The most orthognathic surgical patients were in the age group of 21-25 years and the difference in the number of male and female patients was only small, Cases of orthognathic surgery in patients with class dentoskeletal Angle classification III is the most handled case by the Department of Oral and Maxillofacial Surgery Dr. Hasan Sadikin Bandung in the period 2006-2011 reached $92.31 \%$ of all orthognathic surgery cases or 24 cases. (4) Most orthognathic surgical patients with Class III dentoskeletal classification have an anterior open bite relation. The most commonly performed surgical techniques for patients with Class III dentoskeletal classification are bimaxillary surgical techniques with a combination of Le Fort 1 osteotomy techniques on the maxilla and sagittal split osteotomy and genioplasty of the mandible.
\end{abstract}

Keywords: Orthognathic surgery, Angle classification, class III dentoskeletal 


\section{INTRODUCTION}

People are starting to realize the importance of dental aesthetic necessities besides the important of body health. Treatment by orthodontist specialists is believed by the community, is to improve the position of the teeth, jaw deformity, and dental aesthetics. However, more severe level of deformity or dentofacial deformity unable to be treated just only with conventional orthodontic treatment. This is because it requires a combination of orthodontic treatment and orthognathic surgical treatment to achieve maximum results.

Angle classification is a classification commonly used for malocclusion in the field of orthodontics. Angle can divides the tooth relationship into three classes based on the relationship in the transverse direction. The Angle then classifies malocclusions into three classes based on the relationship between the maxillary first permanent molars and mandibular first molars. Class III dentoskeletal classification has skeletal manifestations seen from the relation between the upper jaw and the lower jaw. Mandibular prognation is one of the skeletal features of Class III dentoskeletal classification or defined as mesiocclusion. The prevalence of class III dentoskeletal occurrence in Asian populations is much higher than Caucasian racial populations. Seen from skeletal relationships in class III dentoskeletal angles, facial concavity profiles are often found concretely from the lateral direction, affecting the patient's facial appearance.

According to Proffit et al., Only $35 \%$ of the population had normal occlusion, while $60 \%$ of the population had malocclusion, and $5 \%$ had disgnative abnormalities or dentofacial deformities that required orthodontic and surgical treatment. Disgnathy is a form of jaw deformity, which is an imbalance in the anatomical relationship and function between the upper jaw and the lower jaw. Disgnathic abnormalities are usually followed by a state of malocclusion and often accompanied by a deviation that affects both aesthetically and functionally. Combination indication of orthodontic treatment and orthognathic surgery are performed when growth modification treatments and camouflage orthodontic treatments cannot achieve satisfactory results. Edward Angle argued that the results of surgery would be better when orthodontic and splint occlusal treatments were performed. In the year of 1980, the application of RIF (Rigid Internal Fixation) in maxillofacial surgery made it possible to fix the jaw, change the shape of the chin in three directions, and reposition the dentoalveolar segment.

RSUP Dr. Hasan Sadikin is a referral hospital for orthognathic surgery that has performed various orthognathic surgical procedures, especially with Class III dentoskeletal Angle abnormalities. Therefore, through this study the authors would like to further explore the management of orthognathic surgery and the abnormalities encountered in patients with Class III Angle dentoskeletal classification in the Oral and Maxillofacial Surgery Department of RSUP Dr. Hasan Sadikin in the period 2006-2011.Aim of research is to obtain data of Orthognathic surgery case overview in patients with class III dentoskeletal angle classification

\section{METHODS}

This type of research is using a retrospective descriptive method by taking secondary data from medical record cards of orthognathic surgery

Tabel 1. Number of orthognathic surgical patients in oral and maxillofacial surgery dr. Hasan sadikin bandung in 2006-2011

\begin{tabular}{cc}
\hline Year & Number of Orthognathic Surgery Patients \\
\hline 2006 & 3 \\
2007 & 6 \\
2008 & 2 \\
2009 & 4 \\
2010 & 5 \\
2011 & 6 \\
\hline Total & 26 \\
\hline
\end{tabular}

Tabel 2. Number and percentage of patients in orthognathic surgical cases in the department of oral and maxillofacial surgery dr. Hasan sadikin bandung in 20062011 based on gender

\begin{tabular}{ccc}
\hline Gender & $\begin{array}{c}\text { Number of patient cases } \\
\text { who undergo Orthognathic } \\
\text { Surgery in the year of } \\
\text { 2006-2011 }\end{array}$ & Percentage \\
\hline Male & 12 & $46.15 \%$ \\
Female & 14 & $53.85 \%$ \\
\hline
\end{tabular}


cases, especially in patients with a diagnosis of Class III dentoskeletal classification that is performed orthognathically in the Oral and Maxillofacial Surgery Department of RSUP Dr. Hasan Sadikin 2006-2011 period. The population in this study were all medical record data of patients undergoing orthognathic surgical treatment in the Oral and Maxillofacial Surgery Department of RSUP Dr. Hasan Sadikin 2006-2011 period. The sample in this study is medical record data of patients with Class III dentoskeletal classification performed orthognathic surgery in the period 2006-2011 then classified by year of surgery, sex, age, Angle classification, state of anterior open bite, location of surgery, and technique used in surgery. The research of used instrument was a patient medical record card which was treated for orthognathic surgery in the Oral and Maxillofacial Surgery Department of RSUP Dr. Hasan Sadikin 2006-2011 period. Data obtained from observations obtained the frequency of each variable, then calculated in the form of a percentage and presented in the form of tables or diagrams.

\section{RESULTS}

The number of patients undergoing orthognathic surgical treatment in the Central Operating Room (COT) of RSUP Dr. Hasan Sadikin Bandung by the Department of Oral and Maxillofacial Surgery in the period 2006-2011 was 26 people. Orthognathic surgery patients in the Department of Oral and Maxillofacial Surgery Dr. Hasan Sadikin Bandung the most in the year of

Tabel 3. Number of orthognathic surgical patients in oral and maxillofacial surgery dr. Hasan sadikin bandung in 2006-2011 based on age groups

\begin{tabular}{ccc}
\hline Gender & Number of patient cases who undergo Orthognathic Surgery in the year of 2006-2011 & Percentage \\
\hline $11-15$ years old & 2 & $7,69 \%$ \\
$16-20$ years old & 10 & $38,46 \%$ \\
$21-25$ years old & 12 & $46,15 \%$ \\
$26-30$ years old & 2 & $7,70 \%$ \\
\hline
\end{tabular}

Tabel 4 number of patient cases who undergo orthognathic surgery at oral surgery department and maxillofacial rsup dr. Hasan sadikin bandung in the year of 2006-2011 based on the dentoskeletal angle classification.

\begin{tabular}{cc}
\hline Dentoskeletal angle Classification & Number of patient cases who undergo Orthognathic Surgery \\
\hline Class I & 0 \\
Class II & 2 \\
Class III & 24 \\
\hline
\end{tabular}

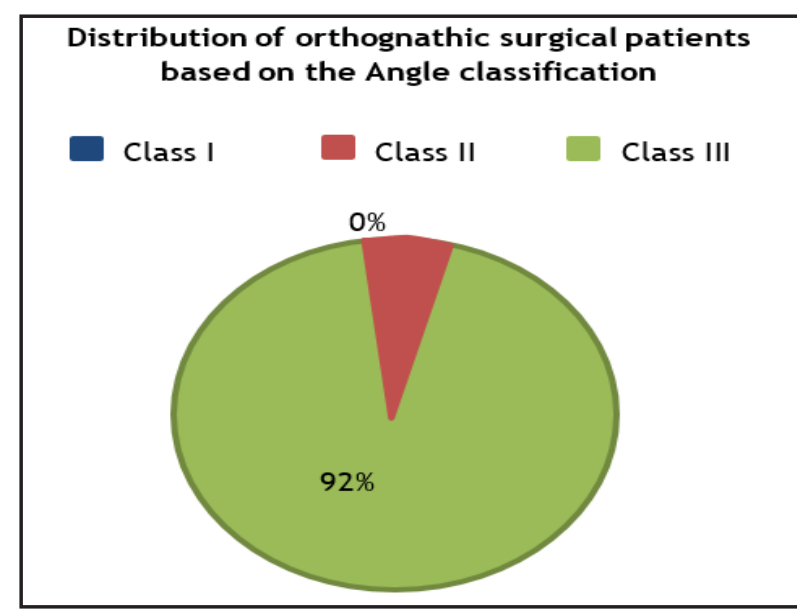

Diagram 1. Distribution of orthognathic surgery patients cases in the oral and maxillofacial surgery department of rsup dr. Hasan sadikin based on dentoskeletal angle classification

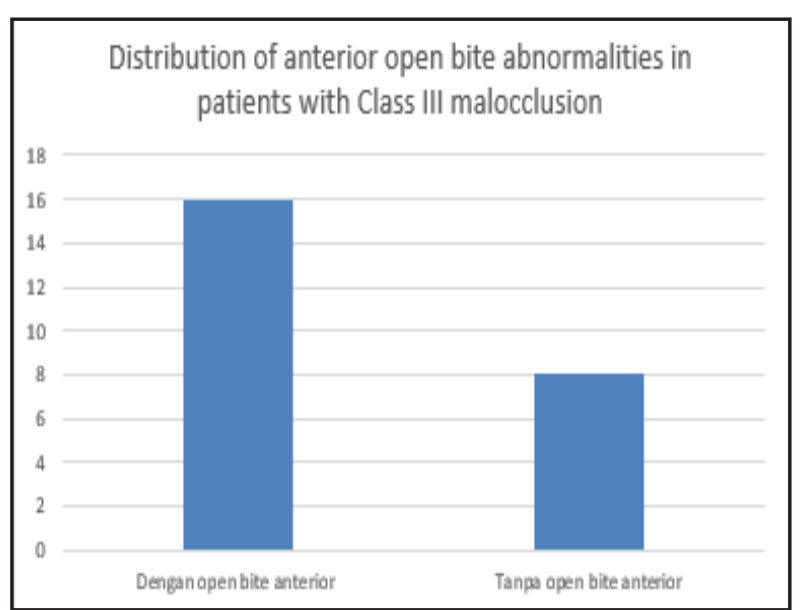

Diagram 2. Comparison of open bite anterior disorders in orthognathic surgical patients with class iii dentoskeletal angle classification in the oral and maxillofacial surgery department of rsup dr. Hasan sadikin 2006-2011 


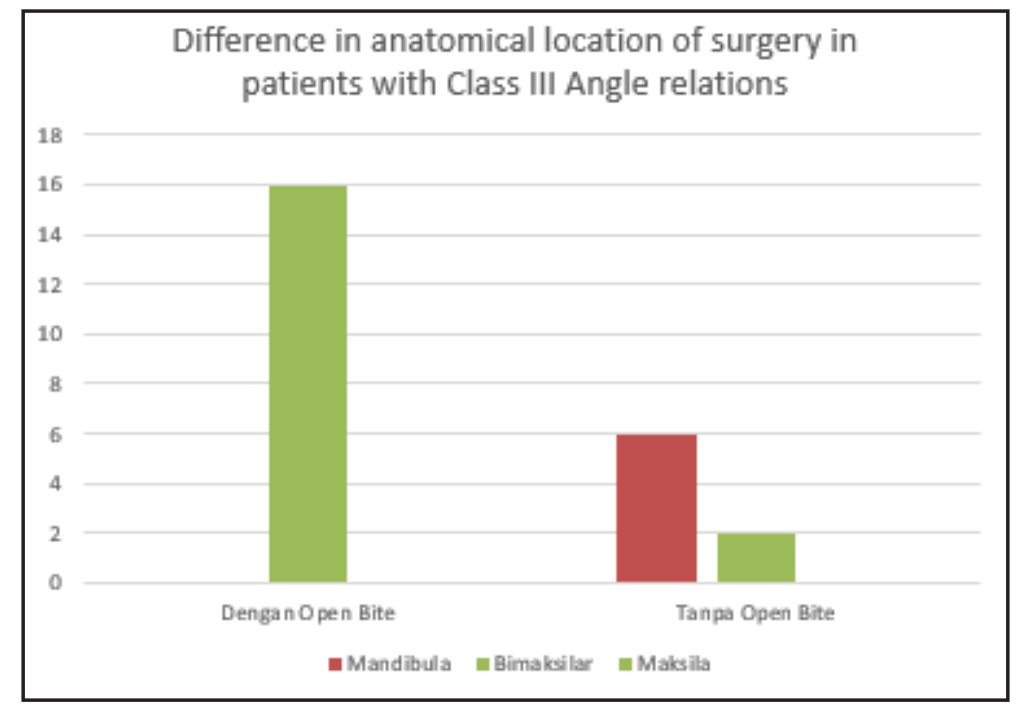

Perbedaan Lokasi Pembedahan pada Pasien Bedah Ortognati dengan Klasifikasi Dentoskeletal Angle Kelas III dengan dan Tanpa Open Bite di Bagian Bedah Mulut dan Maksilofasial RSUP Dr. Hasan Sadikin Tahun 2006-2011

Tabel 5. Number and percentage of patients with orthognathic surgery with class iii dentoskeletal angle classification in the oral and maxillofacial surgery department of rsup dr. Hasan sadikin bandung in 2006-2011 based on surgical techniques used

\begin{tabular}{lcc}
\hline \multicolumn{1}{c}{ Surgical Technique } & Number of Patients with Class III Relationship & Percentage \\
\hline Le Fort 1 + Osteotomy Ramus Vertical + Genioplasty & 5 & $20,83 \%$ \\
Le-Fort-1 + Osteotomy Sagital Split + Genioplasty & 8 & $33.33 \%$ \\
Le-Fort 1 + Osteotomy Sagital Split & 4 & $16,67 \%$ \\
Osteotomy Sagital Split & 4 & $16,67 \%$ \\
Genioplasty & 2 & $8,33 \%$ \\
Osteotomy Sagital Split + Genioplasty & 1 & $4,17 \%$ \\
\hline
\end{tabular}

2007 and 2011, namely 6 patients. The number of patients undergoing orthognathic surgical treatment each year can be seen in table 1 .

Based on gender, the number of disgnatized patients who undergoing orthognathic surgical treatment at RSUP Dr. Hasan Sadikin had almost the same number, namely 12 male patients and 14 female patients.

The age group of 21-25 years is the largest age group of surgical orthognathic patients, In total of 12 patients or $46.15 \%$ total number of orthognathic surgery patients in the Oral and Maxillofacial Surgery Department of RSUP Dr. Hasan Sadikin Bandung. Whereas patients with age groups 11-15 years and 26-30 years are the least age groups, namely 2 people each. The number of patients undergoing orthognative treatment by age group can be seen in table 3 .

Based on the Angle classification, there were 24 orthognathic surgical patients with a diagnosis of grade III dentoskeletal angle who were treated with orthognathic surgery and only 2 orthognathic surgical patients with a diagnosis of having a grade III relation. There were no orthognathic surgical patients with a diagnosis of Class I angle relations. Angle classification can be seen in table 4 and the percentage can be seen in diagram 1 .

The diagram above shows that $92 \%$ of orthognathic surgical patients have a Class III Angle relationship and only $8 \%$ of orthognathic surgical patients have a Class II Angle relation. Based on the anterior tooth overbite relation in patients with an Angle class III relationship, there are 16 patients who have an open bite relation on the anterior teeth. Only 8 patients from Angle III class relationships were treated with orthognathy without an anterior open bite relation.

Based on the anatomical location of orthognathic surgery in patients with Class III Angle relations, bimaxillary surgical procedures 
are most often performed in 16 cases in patients with anterior open bite relations and 2 cases in patients who do not have anterior open bite relations. One jaw surgical procedure is only performed on the mandible, which is in 6 cases in patients with Class III Angle relationships without anterior open bite relations. There is no one-jaw surgical procedure in the maxilla.

\section{DISCUSSION}

In the first table, it shows that there are still a few orthognathic surgery cases in the Oral and Maxillofacial Surgery Department of RSUP Dr. Hasan Sadikin Bandung. This might be due to the lack of public knowledge and the lack of socialization about orthognathic surgery, together with high cost of undergoing orthodontic treatment and orthognathic surgery. In addition, there are many treatment procedures that must be taken both before and after surgery, causing the duration of orthodontic combination surgery and orthognathic surgery to be extended and time consuming. The time required for correction with orthognathic surgery is on average 2 years, from the placement of orthodontic bands to the orthodontic post-surgical treatment (Reyneke, 2011). orthodontic combination treatment with orthognathic surgery.

According to Panula (2003), the main reason patients choose orthognathic surgery as a treatment option is to improve their aesthetics. In addition, functional problems such as mastication and swallowing disorders as well as problems with the temporomandibular joint or pain in the head are also reasons for choosing orthognathic surgery as a treatment option.

Based on the second table, the difference in the number of orthognathic surgical patients by sex is not significant. This relates to the statement of Faure, et al. which states that men and women have the same perception about facial aesthetics which includes the balance of distance between eyes, face height, face width, mouth size, and cheek position. When according to Faure, et al., At least facial attractiveness on a long facial profile with a steep mandibular angle and a high proportion of excess lower third face, as shown in patients with Class III dentoskeletal classification cases in this study.
Based on the results of the study in third table, most orthognathic surgical patients in the age group within 21-25 years. This relates to Erikson's theory of psychosocial development which classifies ages $18-40$ years as the stage of young adulthood (Grysole, 2009). Young adulthood is a period of peak physical development. At the age of young adulthood, more dominant individuals maintain their appearance to look attractive. (Damaris, 2008). According to Saomah (2011), physical abnormalities such as physical disabilities, physical health, and unattractive appearance at young adulthood can cause the individual's distrust so that it can be difficult to adjust to social life, find work, and find a life partner.

Based on the results of the study in table 4 and diagram 1., almost all orthognathic surgery patients handled by the Oral and Maxillofacial Surgery Department of RSUP Dr. Hasan Sadikin is included in the class III dentoskeletal Angle classification which is $92 \%$. Based on the research of Soh, et al., (2005), $51.7 \%$ of the Malay ethnic population had class I malocclusions, $26.27 \%$ had class III malocclusions, $18.3 \%$ and $3.3 \%$ had class II malocclusions division 1 and 2 The prevalence of anterior cross bite, which is characteristic of grade III skeletal malocclusion, reaches $21.7 \%$. Zhou, et al., (2001) also explained that the prevalence of class III malocclusion with mandibular hyperplasia in Asian populations is higher than in Caucasian populations.

No patients with Class I Angle dentoskeletal malocclusion were treated with orthognathic surgery. This is because it was not a strong indication for orthognathic surgical treatment, as it clinically the relationships of molar, canine, incisor and skeletal teeth are neutroclusions, unless the patient wants to correct tooth structure abnormalities in a short period of time compared to a single orthodontic treatment that requires more time or there are abnormalities in the dimension and jaw relation in the transverse direction and / or vertical.

Abnormalities in Class I Angle relations treated with orthognathic surgery are in the state of bimaxillary protrusion, open bite, and deep bite. If surgical treatment is an option, the surgical plan which will be chosen is segmental osteotomy, but not corpus osteotomy. 
According to Mucedero, et al., A quarter of patients with class III dentoskeletal require surgical therapy as a correction for dentoskeletal disharmony. Surgical sagittal osteotomy split techniques or vertical ramus osteotomy are indicated to improve skeletal relationships in Class III dentoskeletal angles for repositioning the mandible to the posterior. Genioplasty can be used to reposition the chin in the anteroposterior, midsagital, and vertical directions (Reyneke, 2003). If Class III dentoskeletal is caused due to mandibular prognation accompanied by maxillary retrusi, bimaxillary surgery is an indication of treatment due to large anteroposterior mismatch that requires repositioning of both jaws to improve jaw dimensions and relations.

The skeletal open bite state is a complex dentofacial deformity and has the characteristics of an increase in lower third face height, short posterior facial height, steep mandibular angle, inverted or flat occultal mandible. Tuinzing, et al., Classified the mandibular prognation which is a characteristic class III dentoskeletal into type A and type B. Type A is a state of mandibular prognation that is not accompanied by an anterior open bite state, and type $B$ is a state of mandibular prognation accompanied by anterior open bite and angle the mandible is steep. This type of difference determines the orthognathic surgical treatment plan. Enacar et al. argues that bimaxillary surgical procedures should be used if there is a change in the shape of the occlusal plain. Le Fort 1 osteotomy with maxillary repositioning of the maxilla to increase anterior dental exposure and clockwise mandibular autorotation is the best treatment for patients with excess maxilla towards the vertical. If mandibular autorotation is not enough to correct anteroposterior abnormalities, a bimaxillary procedure is recommended. Mandibular reposition to the posterior is performed until the balance of facial size is fulfilled. Bimaxillary surgical procedures are also used in patients with facial asymmetry. Bimaxillary surgery is used to achieve a more ideal, stable facial aesthetic, and to form ideal dental occlusions. Based on the results of the study in the table 5., the orthognathic surgical technique most widely used in patients with Class III Angle dentoskeletal classification is a combination of Le Fort I osteotomy in the maxilla and sagittal split osteotomy and genioplasty in the mandible. Le Fort 1 osteotomy allows the physician to reposition the maxilla in three directions, transversal, sagittal and vertical.4 Maxilla can be repositioned using the Le Fort I osteotomy technique 5-6 millimeters to the anterior and 7-8 millimeters to the superior for stable surgery. Maxilla repositioning to the posterior is not done because it will have a negative impact on the nasolabial angle and.5

Sagittal split osteotomy is an orthognathic surgical technique used to reposition mandible in anteriorly or posteriorly. Based on the research results, the sagittal split osteotomy technique is more often used than vertical ramus osteotomy because it uses post-surgical internal rigid fixation so there is no need to use intermaxillary fixation for 6 weeks which the rigid fixation is done with plates. However, the use of rigid fixation in the mandible may increase the incidence of temporomandibular joint abnormalities compared to the use of non-rigid fixation in ramus vertical osteotomy techniques. Balaji et al. argues that good bone contact after a sagittal split osteotomy can accelerate healing. The disadvantages of this technique are the high risk of inferior alveolar nerve injury and the costs incurred compared to ramus vertical osteotomy due to the use of rigid fixation.

Vertical ramus osteotomy is an orthognathic surgical technique for repositioning the mandible to the posterior. This technique has several advantages compared to sagittal split osteotomy such as the incidence of injury to smaller nerves, easier technique, reduced surgical time, and the ability to produce biological balance from the condyle (Hwang, 2009). The disadvantage of the vertical ramus osteotomy technique is that patients are required to use intermaxillary fixation for six weeks. Posterior repositioning of the mandible using the sagittal split osteotomy technique or ramus vertical osteotomy can improve facial aesthetics from the frontal or lateral direction. According to Epker, et al., Repositioning the mandible to the posterior can reduce the angle of the chin, increase the exposure of the upper lip vermilion, and reduce the height of the lower third of the face and in the lateral direction of the face can reduce the protrusion of the chin, reduce eversion of the lower lip, shorten the distance of the neck with the chin, and improve 
paranasal shape. Genioplasty techniques are used in almost all cases of orthognathic surgery in patients with Class III dentoskeletal classification. This is because most dentofacial deformities involve protrusion or retrusiation of the mental region which has a large effect on the balance of the maxillofacial area. Genioplasty is used to achieve good anteroposterior, vertical, and facial midsagital proportions. Increased cooperation between orthodontic specialists. and oral surgery as well as the advancement of orthodontic techniques for the preparation of pre-surgery causing segmental osteotomy is rarely used. As a conclusion, bone incisions in segmental osteotomy between tooth roots can endanger periodontal tissue and vascularity of teeth.

\section{CONCLUSION}

In the period 2006-2011, the Department of Oral and Maxillofacial Surgery Dr. Hasan Sadikin handled 26 orthognathic surgical patients, The most orthognathic surgical patients were in the age group of 21-25 years and the difference in the number of male and female patients was only small, Cases of orthognathic surgery in patients with class dentoskeletal Angle classification III is the most handled case by the Department of Oral and Maxillofacial Surgery Dr. Hasan Sadikin Bandung in the period 2006-2011 reached $92.31 \%$ of all orthognathic surgery cases or 24 cases. (4) Most orthognathic surgical patients with Class III dentoskeletal classification have an anterior open bite relation. The most commonly performed surgical techniques for patients with Class III dentoskeletal classification are bimaxillary surgical techniques with a combination of Le Fort 1 osteotomy techniques on the maxilla and sagittal split osteotomy and genioplasty of the mandible.

\section{REFERENCES}

1. Reyneke, Johan P. Essentials of orthognathic surgery. $1^{\text {st }}$ ed. China: Quintessence Book. 2003. p. 13-61.

2. Premkumar S. Prep Manual for undergraduates orthodontics. New Delhi: Elsevier. 2008. p. 125-127, 162-164.

3. Zhou YH, Hägg U, Rabie AB. Concerns and motivations of skeletal class III patients receiving orthodontic-surgical correction. Int J Adult Orthod Orthognath Surg 2001;16:7-17

4. Proffit WR. Contemporary Orthodontics. $4^{\text {th }}$ ed. Missouri: Mosby. 2007. p. 686-701.

5. Heasman, Peter. 2003. Master Dentistry. Volume I. Spain: Churchill Livingstone. 137138.

6. Panula K. Correction of Dentofacial Deformities with Orthognathic Surgery: Outcome of Treatment with Special Reference to Costs, Benefits and Risks. Thesis. Available from: http://herkules.oulu.fi/ isbn9514269934/html/index.htmloulu [Cited 12 Feb 2012]. 2003.

7. Faure JC, Rieffe C, Maltha JC. The influence of different facial components on facial aesthetics. Eur J Orthod. 2002 Feb;24(1):1-7.

8. Soemantri ESS, Astuti IA. Sepuluh Tahun Perawatan Bedah Ortognati di Fakultas Kedokteran Gigi Universitas Padjadjaran (1990-2000). Bandung: Fakultas Kedokteran Gigi Universitas Padjadjaran. 2000.

9. Mucedero M, Coviello A, Baccetti T, Franchi L, Cozza P. Stability factors after double-jaw surgery in class III malocclusion - A systematic review. Angle Orthod. 2008 Nov;78(6):114152.

10. Epker, Bruce N. Dentofacial Deformities: Intergrated Orthodontic and Surgical Correction Volume II. $2^{\text {nd }}$ ed. New York: Mosby. 1995. p. 569-571, 574-576, 849.

11. Tuinzing DB, Greebe RB, Dorenbos J. 1993. Surgical Orthodontics: Diagnosis and Treatment. J Oral Maxillofac Surg 1994;52(6):653.

12. Enacar A. Effects of single or double-jaw surgery on vertical dimension in skeletal class III patients. Int J Adult Orthod Orthognath Surg 2001;16:30-5.

13. Stansbury CD, Evans CA, Miloro M, BeGole EA, Morris DE. Stability of open bite correction with sagittal split osteotomy and closing rotation of the mandible. J Oral Maxillofac Surg. 2010 Jan;68(1):149-59.

14. Arad I, Jandu J, Bassett P, Fleming PS. Influence of single-jaw surgery vs bimaxillary surgery on the outcome and duration of combined orthodontic-surgical treatment. Angle Orthod. 2011;81:983-7.

15. Kitahara T, Nakasima A, Kurahara S, Shiratsuchi 
Y. Hard and soft tissue stability of orthognathic surgery: sagittal split ramus osteotomy and intraoral vertical ramus osteotomy. Angle Orthod. 2009;79:158-165.)
16. Kim SK, Kim SG. Analysis of soft tissue changes after genioplasty in skeletal class III dentofacial deformity. Yonsei Med 2009;50(6):814-7. 